\title{
A TRANSIÇÃO DO ENSINO PRESENCIAL PARA O ENSINO REMOTO À DISTÂNCIA EM MEIO AO COVID-19
}

\section{THE TRANSITION FROM PRESENTIAL EDUCATION TO REMOTE DISTANCE TEACHING IN THE COVID-19}

\author{
Jessiane Dayane Soares da Silva ${ }^{38}$ \\ Mariana de Araújo Cabral ${ }^{39}$ \\ Sandra Cristina Moraes de Souza ${ }^{40}$
}

\section{RESUMO:}

Em época de isolamento físico no Brasil devido a pandemia da Covid-19 o ensino presencial precisou se transportar para os meios digitais. Surge o interesse em compreender como essa transição repentina do ensino presencial para o ensino remoto impactou na percepção da aprendizagem dos alunos do ensino superior. Este estudo é de natureza quantitativa. O instrumento definido para coleta de dados foi um questionário online com 29 (vinte e nove) perguntas que foi enviado por meio de um link disponibilizado pelo google forms. Com ajuda do software PSPP, foi feita uma análise simples e cruzada. Como resultado, constatou-se que a percepção dos alunos em relação a essa transição ainda está em construção, o que sugere o forte impacto da mudança, que exigiu dos docentes e discentes uma nova forma de interagir na sala de aula. A pandemia também colocou em evidência a desigualdade social em relação ao uso das TIC's, de um lado jovens com seu computador e acesso à internet, de outro lado, jovens sem equipamentos e acesso à internet.

Palavras-chave: Ensino Presencial. Ensino Remoto. Covid-19. Aprendizagem.

\section{ABSTRACT:}

In times of physical isolation in Brazil due to the Covid-19 pandemic, face-to-face teaching had to be transported to digital media. Interest in understanding how this sudden transition from face-to-face to remote teaching impacted the perception of higher education students' learning. This study is of a quantitative nature. The instrument defined for data collection was an online questionnaire with twenty-nine questions that was sent through a link provided by google forms. With the help of PSPP software, a simple cross-sectional analysis was performed. As a result, it was found that the students' perception of this transition is still under construction, which suggests the strong impact of the change, which required teachers and students a new way to

\footnotetext{
${ }^{38}$ Aluna do curso de Graduação em Psicopedagogia pela UFPB. E-mail: jessianedayanev@gmail.com

${ }^{39}$ Aluna do curso de Graduação em Psicopedagogia pela UFPB e do Curso Tecnólogo em Gestão Financeira no UNIESP. E-mail: psicomarianacabral@gmail.com

${ }^{40}$ Doutora em Educação pela Universidade Federal Fluminense - UFF. Professora do Centro de Educação da Universidade Federal da Paraíba - UFPB. E-mail: profsandrapsico@hotmail.com
} 


\section{RevistAleph}

interact in the classroom. The pandemic also highlighted the social inequality in relation to the use of ICTs, on the one hand, young people without computers and access to the Internet, on the other.

Keywords: Regular teaching. Remote Teaching. Covid-19. Learning.

INTRODUÇÃO

Mediante um cenário de grande uso das Tecnologias da Informação e da Comunicação ( $T I C^{\prime}$ s), as modalidades de ensino com uso das redes digitais são evidenciadas como habilitadas a atender educandos de forma flexível, além de possibilitar a potencialização da aprendizagem. Todavia, junto a esse debate, questionase a qualidade do ambiente virtual, o enfoque da educação, a formação docente para uso específico dessas metodologias ativas e a capacidade da internet de acesso dos professores e alunos.

Ainda assim, em 2005 o Ministério da Educação (MEC) promulgou o decreto no 5.662 que regulamenta o art. 80 da Lei de Diretrizes e Bases da Educação Nacional (LDB, p.52), que diz que "o poder público incentivará o desenvolvimento e a veiculação de programas de ensino a distância, em todos os níveis e modalidades de ensino, e de educação continuada". Ainda de acordo com o MEC, as instituições que desejarem ofertar o ensino à distância (EaD) devem solicitar um credenciamento. Contudo, em casos emergenciais a LDB autoriza a realização de atividades à distância nas seguintes modalidades: ensino fundamental, ensino médio, ensino profissional técnico de nível médio, educação de jovens e adultos, ensino superior e educação especial.

Todavia, em meio a uma pandemia da Covid-19 as instituições educacionais tiveram que fechar suas portas temporariamente e deslocar as aulas presenciais para 0 ambiente virtual, o que se configurou como um desafio para a comunidade pedagógica. Nessa conjuntura, surge a discussão sobre as diferentes modalidades de ensino por meio das TIC's e as modificações que decorrem dessa transição do presencial para o que chamamos de remoto. Sabendo que as mudanças causadas pela pandemia foram repentinas, não houve tempo para planejamento e adaptação no âmbito educacional, o que sugere um descontentamento em relação ao processo de ensino-aprendizagem nos meses iniciais de aulas virtuais, que pode ser visto em redes de instituições privadas e públicas. 


\section{RevistAleph}

A partir disso, surge a necessidade de compreender as primeiras impressões causadas em alunos do nível médio e superior, visto que a transição supracitada ocorreu de forma brusca. Faz-se pertinente saber quais as metodologias usadas, visto que esse cenário é novo e tende a ressignificar as discussões acerca do uso das TIC's na educação. Portanto, houve a formulação de um questionário online com 29 (vinte e nove) perguntas de múltipla escolha e 3 (três) perguntas abertas. A divulgação ocorreu por meio das redes sociais com a técnica bola de neve, e em seguida, houve análise dos dados pelo software PSPP e criação dos gráficos pelo Google Sheets. O formulário foi respondido do dia 09 de abril de 2020 à 16 de abril de 2020 .

Nosso objetivo geral foi compreender os aspectos iniciais do processo de transição do ensino presencial ao ensino online para estudantes do superior em meio a pandemia da Covid-19. Obteve-se como específicos: identificar as primeiras percepções mediante nível de satisfação no ensino remoto, verificar possível disparidade entre instituições públicas e privadas, e discutir a aplicabilidade das redes digitais no cenário educacional mediante situações emergenciais.

\section{REFERENCIAL TEÓRICO}

Com a ascendência das redes digitais das TIC's como meio potencializador da veiculação ou mediação de conhecimento e informações (SANTOS, 2019), surgem debates acerca das provocações causadas por ela diante de aspectos de socialização, comunicação e até da educação. No âmbito educacional, o ciberespaço tem sido impulsionado por meio de Ambientes Virtuais de Aprendizagem (AVA), fóruns de discussão, repositório de objetos educacionais, disseminação de material científico e outros. Por isso, encontram-se diversos termos para referenciar as modalidades que fazem uso dessas tecnologias, como: ensino híbrido, educação à distância (EaD), ensino online, e outros. (SANTOS; CARVALHO; PIMENTEL, 2016).

O ensino híbrido apresenta uma mesclagem entre o presencial e o virtual, dependendo da metodologia que será utilizada. Segundo Bacich (2016, p. 679-680), essa concepção está atrelada ao EaD, visto que "em alguns casos, algumas disciplinas são ministradas na forma presencial e, outras, ministradas apenas à distância". Porém, algo 


\section{RevistAleph}

que as difere é que a modalidade híbrida se baseia na personalização do ensino (BACICH, 2016), enquanto que o EaD é caracterizado por um formato que pode ser padronizado para um grande contingente de alunos. Todavia, ele dispõe de uma flexibilidade maior em relação ao horário e dia de estudo, pois permite que, tanto o professor quanto o aluno, estejam em ambientes físicos e espaços temporais diferentes. (COSTA, 2017).

Outro processo de ensino-aprendizagem que pode ser confundido é a modalidade de ensino online, pois alguns a discutem como sinônimo ou como uma evolução do EaD. Entretanto, conforme Santos (2019) explica, há um distanciamento geográfico entre aluno-aluno e aluno-professor, mas ainda assim ocorre interatividade por meio de momentos síncronos e assíncronos, e divulgação de materiais hipertextuais mediante um AVA. Sendo assim, essa modalidade se apresenta em encontros presenciais, à distância e híbridos.

A educação online não é simplesmente sinônimo de educação a distância. A educação online é uma modalidade de educação que pode ser vivenciada e exercitada tanto para potencializar situações de aprendizagem mediadas por encontros presenciais; a distância, caso os sujeitos do processo não possam ou não queiram se encontrar face a face; ou híbridos, quando os encontros presenciais podem ser combinados com encontros mediados por tecnologias telemáticas. (SANTOS, 2019, p. 61-62)

A chamada educação online visa uma educação de qualidade que promove "a (co)autoria do aprendente, a mobilização da aprendizagem crítica e colaborativa, a mediação docente voltada para a interatividade e partilha". (SANTOS; CARVALHO; PIMENTEL, 2016). Mediante isso, o processo educacional não é restrito a uma dimensão conteudista em que o professor transfere o que sabe, mas sim de formação cultural, social, política e profissional de discentes atuantes na sociedade.

Infelizmente, o paradigma de produção industrial ainda é atuante nas modalidades e níveis de ensino no Brasil, onde é possível ver um caráter quase exclusivamente conteudista para enviar ao mercado de trabalho. Por isso, no debate de educação online, é preciso apontar que o ambiente das redes digitais não determina a qualidade do processo de troca de conhecimento, como afirma Santos $(2019$, p. 76), 


\title{
RevistAleph
}

tudo vai depender "do movimento comunicacional e pedagógico dos sujeitos envolvidos para a garantia da interatividade e cocriação".

Portanto, percebe-se que todas as modalidades supracitadas usam a tecnologia ao seu favor, seja como forma de potencializar, ou como meio de disponibilizar esse ensino-aprendizagem para aqueles que não podem estar presencialmente em uma instituição. Contudo, essa manutenção tecnológica para usos pedagógicos exige um processo de inclusão digital que supõe um deslocamento do que é palpável para o universo que há dentro do ciberespaço. (SANTOS, 2019). Para isso, discentes e docentes precisam ter um conhecimento sobre informática básica, como uso de planilhas, acesso aos portais de ensino e pesquisa, e outros. Mas vai muito adiante disso,

\begin{abstract}
Além de infraestrutura adequada de comunicação, de modelos sistêmicos bem planejados e projetos teoricamente bem formulados, o sucesso de qualquer empreendimento nesta área depende, fundamentalmente, de investimentos significativos que deverão ser feitos na formação de recursos humanos, de decisões políticas apropriadas e oportunas, amparadas por forte desejo e capacidade de realização. (MORAES, 1998, p.1 apud MARQUES e SOUZA, 2016, p. 1)
\end{abstract}

Portanto, a educação com uso do virtual só é possível com a acessibilidade a aparelhos como computadores, internet de qualidade, conhecimento sobre seus usos, formação docente e investimentos em políticas públicas que sejam favoráveis. Vale ressaltar que esse encaminhamento que chamamos anteriormente de inclusão digital, é um processo muito amplo que envolve também o debate de exclusão social, visto que, nem todas as camadas da sociedade possuem condições de se apropriar desses recursos.

Segundo dados do Instituto Brasileiro de Geografia e Estatística (IBGE, 2018), 79,1\% dos domicílios possuíam acesso à internet em 2018, dentre os quais, as regiões com menor percentual de uso são o Nordeste e o Norte. Em contraposição a esses, destacam-se 14.991 mil residências sem acesso, tendo alegado falta de interesse $(34,7 \%)$, custo caro para a banda larga $(25,4 \%)$, moradores sem saber utilizar $(24,3 \%)$ e também custo alto para compra de equipamentos eletrônicos para poder desfrutar do ciberespaço (4,7\%). Diante dessas informações, sabe-se que há um grande contingente 


\section{RevistAleph}

de domicílios com essa conectividade, mas não há informações claras sobre a qualidade desse acesso.

O Instituto Nacional de Estudos e Pesquisas Educacionais Anísio Teixeira (INEP, 2020) divulgou os dados acerca dos candidatos inscritos para o Exame Nacional de Ensino Médio (ENEM). Dentre as informações de fatores de contexto para os estudantes, 2.345.467 estudantes declararam não ter um computador e 1.140.465 afirmaram não possuir acesso à internet. Com base nisso, surgem questionamentos sobre o real alcance do ensino por mediação das redes digitais para a comunidade estudantil do Brasil.

Em contexto de pandemia do SARS-CoV-2, comumente chamado de Covid-19, as instituições de ensino deslocaram suas aulas presenciais para o modo virtual, visando cumprir a regra de distanciamento físico. Ao entorno disso, levanta-se a discussão sobre a inviabilidade das aulas ocorrerem dessa forma por motivos de falta de preparação dos professores para formulação de metodologias apropriadas para um ensino online, além da falta de acesso dos educandos às tecnologias que possibilitem o contato remoto para ter acesso às aulas.

Segundo o Diário da União de 18 de março de 2020, pela portaria no 343, de 17 de março de 2020, em seu caput nos informa que "Dispõe sobre a substituição das aulas presenciais por aulas em meios digitais enquanto durar a situação de pandemia do Novo Coronavírus - COVID-19". (UNIÃO, 2020). A portaria citada, se refere especificamente à "educação superior integrante do sistema federal de ensino" (UNIÃO, 2020), excluindo da medida os cursos de medicina, assim como práticas de estágio e laboratório de outros cursos.

Todavia, a portaria supracitada foi revogada no dia 16 de junho de 2020, por meio da portaria no 544, que autoriza a substituição das aulas presenciais em um período que se estende até o dia 31 de dezembro de 2020, por parte de instituições do ensino superior do sistema federal. (BRASIL, 2020). O mesmo afirma que vai ser

de responsabilidade das instituições a definição dos componentes curriculares que serão substituídos, a disponibilização de recursos aos alunos que permitam o acompanhamento das atividades letivas 


\section{RevistAleph}

ofertadas, bem como a realização de avaliações durante o período da autorização de que trata o caput. (BRASIL, 2020, p. 62).

Referente aos estudantes de nível médio, o debate girou em torno do ENEM, onde houveram manifestações virtuais, através de influenciadores midiáticos, pedindo o adiamento da prova por causa do acesso à educação dos discentes, que muitas vezes não possuem as condições mínimas para se preparar para o exame em casa. Uma das campanhas mais gritantes nesse momento de manifestação foi o "\#AdiaEnem". Ele evidencia que o MEC insiste em fazer as provas do ENEM, mesmo sabendo que nem todos os estudantes inscritos na prova estão com as mesmas condições de prosseguir seus estudos e serem capacitados para fazer a avaliação.

Ainda assim, a educação online gera a continuidade das aulas em meio a situações emergenciais como a pandemia da Covid-19. Contudo, vale ressaltar que a educação vai além do conteúdo que será passado, porém, nos momentos iniciais da transição do presencial ao remoto, não foi possível mensurar as habilidades sociais e críticas trabalhadas no ambiente online.

\section{METODOLOGIA}

O presente trabalho é de natureza quantitativa. Segundo Richardson (1999, p. 70), “o método quantitativo, como o próprio nome indica, caracteriza-se pelo emprego da quantificação, tanto nas modalidades de coleta de informações quanto no tratamento delas por meio de técnicas estatísticas".

O instrumento metodológico utilizado foi um questionário, que segundo Marconi; Lakatos (2018), é um instrumento de coleta de dados constituído por uma série de perguntas, que o participante responde sem necessidade da presença do pesquisador. O questionário online foi enviado por meio de um link disponibilizado pelo google forms, plataforma que utilizamos para elaborar e distribuir para amigos, conhecidos e amigos de amigos por meio de redes sociais como instagram e whatsapp, usando assim, a técnica bola de neve. A pesquisa foi de aplicação não probabilística, mas que segundo Vieira (2011), não invalida a pesquisa. 


\section{RevistAleph}

Contamos com 29 (vinte e nove) perguntas, sendo 3 (três) perguntas abertas e as outras 26 (vinte e seis) de múltipla escolha de acordo com o grau que mais se adequasse à realidade do participante, por meio de uma régua de satisfação que continha as respostas: ruim, regular, bom, ótimo e excelente, enumeradas de 1 (um) a 5 (cinco) na ordem elencada. Os dados foram analisados estatisticamente pelo software PSPP.

Realizamos 6 (seis) perguntas para mapear os participantes, em seguida, 4 (quatro) para compreender os materiais e metodologias utilizados por professores e estudantes, após isso, 9 (nove) perguntas para comparar com as 9 (nove) seguintes, a percepção acerca do antes e durante pandemia, por fim, uma pergunta final para obter uma palavra que representasse o momento passado pelos discentes.

A amostragem foi de 191 (cento e noventa e um) alunos que foram coletados entre 09 de abril de 2020 à 16 de abril de 2020. O universo abordado na pesquisa foi de estudantes de cursinho pré-Enem, ensino médio e superior, tendo a maior aceitação nos dois últimos citados. Acerca das regiões dos discentes, obtivemos respostas do Nordeste em sua maioria, mas também contamos com Norte e Sudeste, devido à técnica de bola de neve. Entretanto, por não haver número significativo de respostas sobre o cursinho pré-Enem, e regiões Sudeste e Norte, optou-se por analisar os dados apenas do ensino médio, superior e dos Estados de Pernambuco e Paraíba, que representam a grande porcentagem de respostas do Nordeste.

A partir disso, restaram 122 (cento e vinte e dois) participantes que foram separados entre instituições públicas e privadas, buscando analisar uma possível disparidade entre os dois grupos, tendo ainda a divisão entre quem sempre estudou na modalidade presencial e quem já estudou à distância por escolha, mas não houve um

número significativo na segunda categoria. As faixas etárias classificadas e separadas, desde menos de 20 (vinte) a mais de 50 (cinquenta), com intervalos de 5 anos.

A tabulação dos dados foi feita com a ajuda do próprio google forms e do software PSPP, tendo sido feita a simples e cruzada. Houve vistoria de forma geral e comparativa entre duas variáveis, como a diferença entre os resultados obtidos com estudantes de ensino público versus privado. A interpretação também se deu por análise 


\section{RevistAleph}

comparativa entre as perguntas que se referiam ao antes da transição e ao depois, com ajuda de tabelas e gráficos para uma melhor visualização.

\section{RESULTADOS E DISCUSSÕES}

Os dados coletados nesse estudo foram organizados conforme as informações presentes nos questionários. Importa dizer que das 29 (vinte e nove) questões abordadas no estudo, foram trazidas para esse artigo apenas 15 questões. 0 critério estabelecido para escolha das questões foram as que mais se aproximaram dos objetivos específicos da pesquisa.

Em relação ao gênero e a faixa etária, a análise de dados agregou 122 respondentes, onde 78 são do sexo feminino $(63,93 \%)$ e 44 do sexo masculino $(36,07 \%)$, tendo em sua maioria pessoas com faixa etária entre 21 e 25 anos (49,1\%), seguidos de indivíduos com menos de 20 anos (32,7\%), como exposto na Figura 1:



Fonte: Dados da Pesquisa (2020)

Já mediante o tipo de instituição em que estão ingressos, encontram-se os dados de que $50 \%$ são de instituições de ensino público e $50 \%$ são de universidades particulares, o que oferece uma dimensão de diferenciação entre esses dois grupos de discentes.

De acordo com a unidade federativa dos universitários, $114(93,4 \%)$ são da Paraíba e 8 (6,5\%) de Pernambuco. Vale salientar que 108 alunos (88,5\%) sempre estudaram de forma presencial e $14(11,4 \%)$ já experienciaram aulas com interferências 


\section{RevistAleph}

das TIC's, como o EaD. Todavia, no momento de coleta de informações, todos eles faziam parte da mesma modalidade de ensino remoto.

Outra questão abordada no questionário foi saber a respeito das práticas mais frequentes de ensino e aprendizagem por parte dos professores e dos discentes em meio às aulas remotas. As respostas indicam que comumente há compartilhamento de vídeos das aulas, atividades por meio de plataformas digitais, trabalhos de final de semestre, disponibilização de slides, atividades práticas em casa, vídeo conferências, aplicação de questionário e outros.

Ainda em relação às estratégias, paralelamente promovem-se a leitura de livros paradidáticos para debates e indicação também de materiais científicos. De certo, percebe-se que há várias metodologias aptas sendo utilizadas para a comunicação em relação aos conteúdos, mas pouco pode ser mensurado sobre a real interatividade entre os indivíduos, inclusive porque os resultados aqui expostos foram coletados nos momentos iniciais do ensino remoto.

Dentre as questões escolhidas, indagou-se qual o nível de aprendizagem percebida por parte dos estudantes, tanto nas aulas presenciais, antes da pandemia, quanto nas aulas virtuais, durante a pandemia. A interrogação se refere à percepção própria que eles possuem acerca dos conhecimentos adquiridos por meio dos processos de ensino utilizados nas aulas. Referente ao contexto presencial, não houve resposta que indicasse um nível "ruim", e em sua maioria, os acadêmicos da rede privada manifestaram uma satisfação “ótima" (52,4\%), seguida de "boa" (22,9\%). Semelhantemente, as porcentagens da rede pública retratam em caráter da aprendizagem percebida "ótimo" (57,3\%) e "bom" (27,8\%), conforme mostra a Figura 2.

Em contraste com o que foi exposto anteriormente, quando se referem às aulas remotas há uma grande diferenciação, especialmente no que diz respeito ao tipo de instituição de ensino. Em universidades particulares, a amostra revela uma satisfação ao responder "bom" (39,3\%). Contudo, nota-se um acréscimo de respostas que exprimem uma satisfação negativa, com índices para "ruim" (14,7\%) e "regular" $(19,7 \%)$. 


\section{RevistAleph}

No caso das instituições públicas, evidencia-se um declínio maior que nos casos de discentes da rede privada. No que diz respeito às aulas remotas, $31,1 \%$ responderam "ruim" e 31,1\% para "regular", enquanto 24,5\% retrataram "bom" em razão ao seu nível de aprendizagem percebida, como mostra a Figura 3. Nesse quesito, faz-se necessário afirmar que a variável usada, não busca avaliar se eles estão aprendendo ou não, mas sim, representar o seu contentamento diante daquilo que eles supõem apreender durante as aulas.

Figura SEQ ARABIC 2 - Nível de satisfação com a aprendizagem percebida no ensino presencial por tipo de instituição.

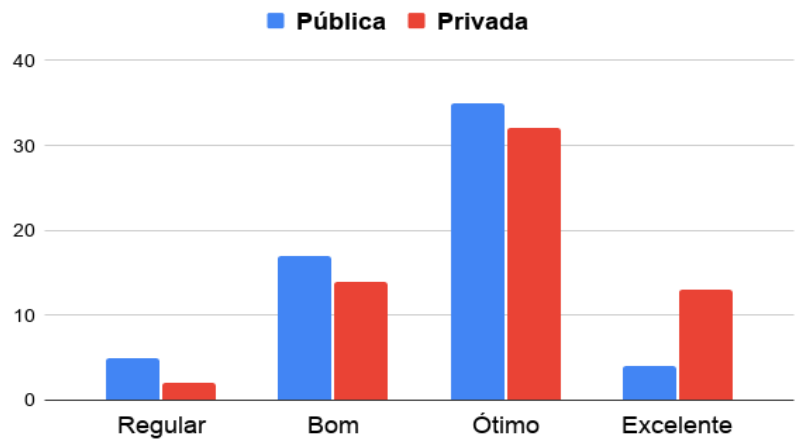

Fonte: Dados de Pesquisa (2020)

Figura SEQ \ARABIC 3 - Nível de satisfação com a aprendizagem percebida no ensino remoto por tipo de instituição.

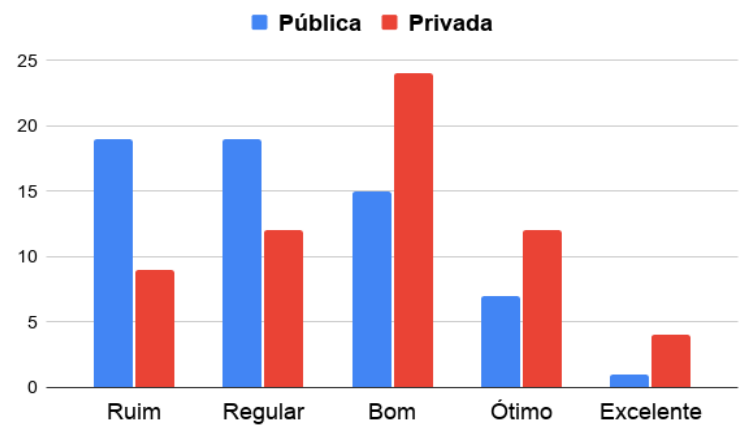

ISSN 1807-6211 [Dezembro. 2020] № 35 


\section{RevistAleph}

Outra discussão levantada foi acerca da satisfação geral em relação ao processo de ensino-aprendizagem, antes e depois da transição, que engloba elementos como o ambiente de sala, os professores, materiais didáticos, e outros fatores. Referente ao momento de encontros presenciais, os dados efetivaram que $50,8 \%$ discentes de universidade pública responderam "ótimo", enquanto 50,8\% de instituições particulares caracterizaram sua satisfação geral como "excelente". Essas representam a maioria das respostas, como pode ser observado na Figura 4.

No entanto, percebe-se uma mudança em relação a satisfação geral nos períodos iniciais do ensino online. Na conjuntura dos respondentes de instituições particulares, houve maior percentual de respostas indicando uma boa satisfação, porém observa-se que há pouca diferenciação entre as que indicam insatisfação. As respostas demarcam 27,8\% para "bom", 22,9\% para "regular" e 27,8 \% para "ruim". Já no contexto de instituições públicas a insatisfação foi mais agravante, pois grande parte respondeu "ruim", o qual equivale a 42,6\%, conforme está perceptível na Figura 5.

Figura 4 - Nível de satisfação com a aprendizagem percebida no ensino presencial por tipo de instituição.

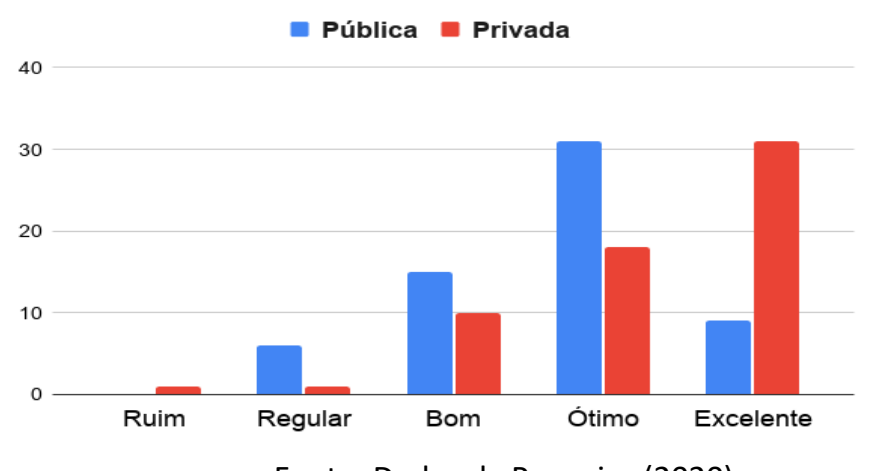

Fonte: Dados da Pesquisa (2020) 


\section{RevistAleph}

Figura 5 - Nível de satisfação com a aprendizagem percebida no ensino remoto por tipo de instituição.



Fonte: Dados da Pesquisa (2020)

Nota-se que os participantes da pesquisa advindos de escolas e universidades públicas se caracterizam com um maior percentual de insatisfação. Assim sendo, supõese que essa conjuntura educacional necessita de mais investimentos para uma educação de qualidade em nível online. Logo, quando se fala sobre essa qualificação de ensino, implica dizer, não apenas sobre os conteúdos a serem veiculados, mas também o caráter protagonista do aprendente enquanto ser político e social.

Ademais, foi abordado no objeto de estudo qual palavra representava a percepção que eles possuíam acerca das aulas à distância que eles estavam vivenciando. Houveram repetições enfáticas de palavras como: insatisfação, desorganização, necessário, estresse, ineficiente, difícil, ruim e acumulativo. Percebe-se que as palavras mais repetidas representam um sentido denotativo negativo.

Em contraposição, encontramos palavras indicando sentido positivo, como: bom e ótimo; os quais foram repetidos sete e cinco vezes, respectivamente. Em acordo aos termos utilizados para referenciar uma satisfação com o ensino dito remoto, nota-se que em sua maioria, elas foram citadas por estudantes da rede privada, o que salienta os dados já supracitados que mostram um descontentamento maior por parte dos advindos de instituições públicas. 


\section{RevistAleph}

Em virtude disso, observa-se que apesar das indicações constitucionais mostrarem que deve haver investimento na educação feita de forma online, há um despreparo nas redes públicas e isso se deve a diversos fatores, como as desigualdades sociais em relação ao acesso à internet, a formação e valorização do trabalho das equipes pedagógicas, e políticas públicas de investimentos monetário para inclusão digital. Em contextos emergenciais, como no caso do distanciamento gerado pela Covid19, as propostas do ensino remoto indicam uma migração do ensino presencial para o ensino feito de forma online de uma hora para a outra, o que acaba gerando resultados insatisfatórios nos momentos iniciais.

Especialistas, como Waldomiro Loyolla ${ }^{41}$, abordam que a rede pública de ensino brasileiro possui conectividade com a internet, porém isso não é bem evidenciado. (BARONE, 2020). Todavia, em situação emergencial, não se trata das escolas que possuem ou não internet, e sim, dos discentes e docentes que possuem acesso de qualidade à internet e um computador ou smartphone que possibilite as práticas de ensino-aprendizagem.

\section{CONSIDERAÇÕES FINAIS}

A partir disso, nota-se que a mudança brusca ocasionada pela situação emergencial da pandemia da Covid-19 afetou a percepção dos escolares e acadêmicos sobre seu processo de ensino-aprendizagem. Nesse caso, vale lembrar que os dados coletados por essa pesquisa agregam uma pequena porcentagem de discentes dos dois Estados da amostra. Ainda assim, cumpre-se o objetivo de compreender os aspectos iniciais do processo de transição do ensino presencial ao ensino online para estudantes do ensino médio e superior em meio a pandemia da Covid-19.

Os resultados também demonstram que um grupo parece ser mais afetado que o outro, é o caso de estudantes de instituições da rede pública, o que leva a crer que apesar do incentivo às políticas públicas, há uma disparidade de acesso às TIC's entre discentes do ensino público e privado. Já que devido o distanciamento físico, pouco importa se as escolas foram informatizadas e possuem acesso à internet, já que alunos

\footnotetext{
${ }^{41}$ Presidente do Conselho Científico da Associação Brasileira de Educação a Distância (ABED).
} 


\section{RevistAleph}

e professores, precisam de conectividade em suas casas para dar continuidade aos estudos.

Campanhas sociais divulgadas principalmente pelas redes sociais demonstram a indignação popular daqueles que foram negligenciados no processo educativo do ensino remoto. Eles apontam que a desigualdade fica clara quando as instituições educativas gritam que a educação não pode parar, mas efetivamente elas não alcançam todos da turma por causa da falta de acesso à internet ou condições mínimas de estudo em casa.

Além disso, a transição do ensino presencial para o ensino remoto ocorreu em contexto de intenso debate acerca da meritocracia no âmbito educacional, o qual acredita que os que alcançam são os mais dedicados e mais bem-dotado intelectualmente, fator esse que ignora as discrepâncias sociais. Portanto, vale ressaltar que os dados aqui expostos apontam para uma situação bem maior que o Brasil estava enfrentando, um contexto de sucateamento da educação pública e desvalorização da formação e trabalho docente.

Se faz necessário um olhar mais cuidadoso para os estudantes do ensino público, mas também vale lembrar dos da rede privada. Apenas ter acesso à internet não é o bastante para que nossos estudantes tenham condições mínimas de estudo, como um computador ou notebook, já que mesmo que o celular possa servir como um suporte, não proporciona a melhor das experiências. Não são todos que possuem um ambiente favorável para concentração, interação e outros fatores importantes para o aprender. Ofertar as ferramentas online, mas esquecer da capacitação por parte dos docentes e discentes, é como pedir para uma galinha voar, ao passo que ela possui as asas, consegue sair do chão, mas não vai muito longe.

Segundo Campos (2019), educar é responsabilidade da família, de ajudar o estudante em seu desenvolvimento pessoal, profissional e sua construção de identidade, enquanto o papel da escola está no ensinar, no qual se refere à cultura, leis e o processo de desenvolvimento. Lembrando que cada um ensina e aprende à sua maneira. Precisamos tratar nossos alunos com equidade, entender como efetivar a 


\section{RevistAleph}

aprendizagem, e tornar prazeroso e dar sentido ao processo dando iguais condições de ensino, pelo menos no que se refere às instituições.

Ainda temos um longo caminho a percorrer, o mundo mudou com a pandemia, e o que conhecemos de instituições de ensino já está mudando. Não sabemos o quanto ainda, mas é certo que teremos resquícios desse contexto turbulento, seja pelos sistemas que tiveram que ser aprimorados rapidamente, seja a forma de atuação dos professores, ou ainda a forma de estudo dos alunos.

\section{REFERÊNCIAS}

BARONE, I. Educação pública na pandemia: faltam estratégias para enfrentar situações como a Covid-19. Gazeta do povo, Brasília, 23 mar 2020. Disponível em: $<$ https://www.gazetadopovo.com.br/educacao/educacao-publica-na-pandemia-faltamestrategias-para-enfrentar-situacoes-como-a-covid-19/>. Acesso em: 14 mai 2020.

BRASIL. LDB: Lei de diretrizes e bases da educação nacional. - Brasília: Senado Federal, Coordenação de Edições Técnicas, 2017.

BRASIL. Portaria no 343, de 17 de março de 2020. Diário Oficial da União, Brasília, DF. 17 de mar. 2020. Seção 1, p. 39.

BRASIL. Portaria no 544, de 16 de junho de 2020. Diário Oficial da União, Brasília, DF, n. 114. 17 jun. 2020. Seção 1, p. 62.

CAMPOS, A. M. A. de. Jogos matemáticos: uma nova perspectiva para discalculia. 2a. ed. Rio de Janeiro: Wak Editora, 2019.

COSTA, A. R. A educação a distância no Brasil: concepções, histórico e bases legais. Revista científica da FASETE, v., n., p. 59-74, 2017.

IBGE. Acesso à internet e à televisão e posse de telefone móvel celular para uso pessoal, 2018. Disponível em: <https://biblioteca.ibge.gov.br/visualizacao/livros/liv101543.pdf >. Acesso em 05 de out. 2020

INEP. Sinopses Estatísticas do Enem. Disponível em: < http://inep.gov.br/web/guest/sinopsesestatisticas-do-enem>. Acesso em: 05 out. 2020.

MARCONI, M.A.; LAKATOS, E. M. Técnicas de pesquisa. 8. ed. São Paulo: Atlas, 2018.

MARQUES, C. L.; SOUZA, A. M. Políticas públicas educacionais no ensino profissionalizante a distância: um olhar sobre a inclusão social. Journal of Research in Special Educational Needs, v. 16, n. 1, 2016. Disponível em: <https://onlinelibrary.wiley.com/doi/epdf/10.1111/14713802.12343> . Acesso em: 21 abr. 2020. 


\section{RevistAleph}

MINISTÉRIO DA EDUCAÇÃO. Decreto № 5.622/05. Brasília, DF, 19 dez. 2005. Disponível em: $<$ http://www.planalto.gov.br/ccivil 03/ Ato2004-2006/2005/Decreto/D5622.htm>. Acesso em: 20 abr. 2020.

RICHARDSON, R. J. Pesquisa social: métodos e técnicas. 3. ed. São Paulo: Atlas, 1999.

SANTOS, E. Pesquisa-formação na cibercultura. Teresina: EDUFPI, 2019.

SANTOS, E. O.; CARVALHO, F. S. P.; PIMENTEL, M. Mediação docente online para colaboração: notas de uma pesquisa-formação na cibercultura. Campinas, SP, Educação Temática Digital, v. 18 , n. 2, p. 23-42, 2016.

VIEIRA, S. Introdução à Bioestatística, 4ạ. Ed. Rio de Janeiro: Elsevier, 2011.

Data de envio: 06/07/2020

Data de aceite: $25 / 11 / 2020$ 